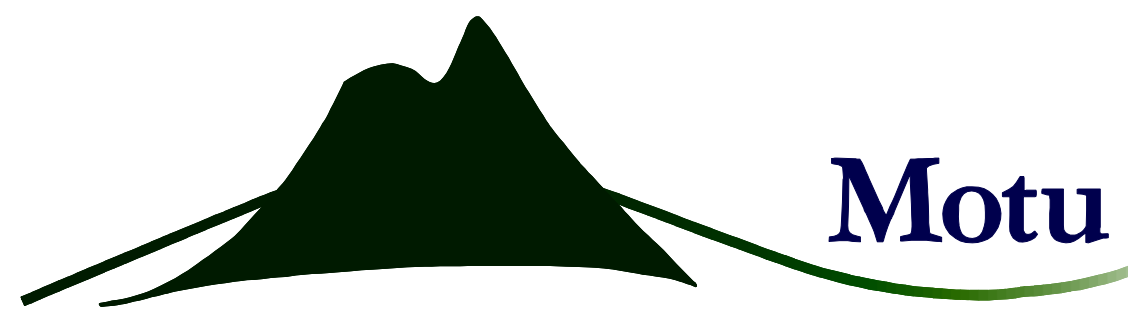

Productivity distributions in New Zealand: The dangers of international comparison

Richard Fabling and Lynda Sanderson

Motu Working Paper 14-16

Motu Economic and Public Policy Research

December 2014 


\section{Author contact details}

Richard Fabling

Independent researcher

richard.fabling@xtra.co.nz

Lynda Sanderson

The Treasury

lynda.sanderson@,treasury.govt.nz

\section{Disclaimer}

The results in this paper are not official statistics, they have been created for research purposes from the Integrated Data Infrastructure (IDI) managed by Statistics New Zealand. The opinions, findings, recommendations and conclusions expressed in this paper are those of the authors not Statistics NZ, the Treasury, or Motu Economic and Public Policy Research.

Access to the anonymised data used in this study was provided by Statistics NZ in accordance with security and confidentiality provisions of the Statistics Act 1975. Only people authorised by the Statistics Act 1975 are allowed to see data about a particular person, household, business or organisation and the results in this paper have been confidentialised to protect these groups from identification. Careful consideration has been given to the privacy, security and confidentiality issues associated with using administrative and survey data in the IDI. Further detail can be found in the Privacy impact assessment for the Integrated Data Infrastructure available from www.stats.govt.nz.

The results are based in part on tax data supplied by Inland Revenue to Statistics NZ under the Tax Administration Act 1994. This tax data must be used only for statistical purposes, and no individual information may be published or disclosed in any other form, or provided to Inland Revenue for administrative or regulatory purposes. Any person who has had access to the unit-record data has certified that they have been shown, have read, and have understood section 81 of the Tax Administration Act 1994, which relates to secrecy. Any discussion of data limitations or weaknesses is in the context of using the IDI for statistical purposes, and is not related to the data's ability to support Inland Revenue's core operational requirements.

\section{Motu Economic and Public Policy Research}

PO Box 24390

Wellington

New Zealand

Email_info@motu.org.nz

Telephone+6449394250

Website www.motu.org.nz

(C) 2014 Motu Economic and Public Policy Research Trust and the authors. Short extracts, not exceeding two paragraphs, may be quoted provided clear attribution is given. Motu Working Papers are research materials circulated by their authors for purposes of information and discussion. They have not necessarily undergone formal peer review or editorial treatment. ISSN 1176-2667 (Print), ISSN 1177-9047 (Online). 


\begin{abstract}
Recent discussions of New Zealand's relative economic performance have drawn a link between firm-level productivity dispersion and a lack of competitive pressure. This note describes a simple example using New Zealand firm-level data which casts doubt on the assertion that New Zealand has a "long tail" of low productivity firms relative to other countries.
\end{abstract}

\title{
JEL code
}

D24

\section{Keywords}

Multifactor productivity (MFP), Dispersion 


\section{Introduction}

Over the last 20 years, advances in the availability and analysis of business microdata across countries have generated a new set of stylised facts, some of which initially seem to be at odds with standard assumptions of competitive markets. In particular, firm-level productivity research "documents, virtually without exception, enormous and persistent measured productivity differences across producers, even within narrowly defined industries" (Syverson, 2011, p326).

More recently, comparisons have been drawn between productivity dispersion in New Zealand and that in other countries. One of these comparisons suggests that labour productivity in New Zealand is more widely dispersed than that in comparator countries. This finding has been used to argue that the New Zealand economy suffers from a lack of competitive pressure. However, international comparisons of this nature are inherently subject to a range of practical and conceptual difficulties. The analysis below describes a simple example using New Zealand firm-level data which casts doubt on the assertion that New Zealand has a relatively wide productivity distribution.

\section{Analysis}

Using data from Statistics New Zealand's Longitudinal Business Database (LBD), we generate measures of multi-factor productivity (MFP) dispersion for New Zealand manufacturing industries. These distributions are compared to those reported by Syverson (2011), citing Syverson (2004) for the United States. The comparison is very partial - we consider productivity dispersion at the level of the enterprise within 2-digit ANZSIC manufacturing industries, while Syverson uses 
plant-level data for 4-digit SIC industries - but is indicative of the key point we wish to emphasize: benchmarking New Zealand against international comparators can only be valid if we are confident that the underlying data and methods of analysis are actually comparable.

A key difference between the LBD and most similar datasets internationally is the coverage of micro-enterprises. As the LBD is based on administrative data from Inland Revenue, it includes a large number of firms which fall beneath standard thresholds for survey data collections. In particular, the US Census of Manufactures classifies most plants with less than five employees as "administrative record" cases, and does not collect data on inputs. In contrast, the LBD includes many very small and even non-employing (working proprietor only) firms (Fabling \& Maré (2015b), Fabling \& Maré (2015a)). We show that this distinction is sufficient to generate an apparent difference between productivity dispersions in New Zealand and the United States.

Table 1 reports measures of productivity dispersion in 2010 for 2-digit manufacturing industries, based on the full population of firms with available productivity data in the LBD (MFP is mean zero within industry by construction). Taking the average dispersion across industries, this shows a difference in logged MFP within industries of 0.904 , translating to an MFP gap of $\exp ^{0.904}=2.47$. That is, firms at the 90th percentile of their industry are, on average, around two and a half times as productive as those at the 10th percentile. A comparison of this figure with the 4-digit average of 1.92 reported in Syverson (2004) would indeed suggest that productivity dispersion in New Zealand is wider than that in the US.

However, a simple restriction to employing firms suggests a very different picture. Table 2 reports the same statistics, but excludes working proprietor only firms. ${ }^{1}$

\footnotetext{
${ }^{1}$ Working proprietor only firms make up over 40 percent of the total firm population, but account for only four percent of measured labour input and one percent of aggregate gross output.
} 
Table 1: MFP dispersion by industry, all firms pooled

\begin{tabular}{|c|c|c|c|c|c|c|}
\hline & $\mathrm{p} 10$ & $\mathrm{p} 25$ & p75 & $\mathrm{p} 90$ & p90-p10 & $\exp (\mathrm{p} 90-\mathrm{p} 10)$ \\
\hline Food, Beverage and Tobacco & -0.389 & -0.197 & 0.158 & 0.456 & 0.845 & 2.33 \\
\hline $\begin{array}{l}\text { Textile, Clothing, Footwear and Leather } \\
\text { Manufacturing }\end{array}$ & -0.497 & -0.177 & 0.246 & 0.544 & 1.041 & 2.83 \\
\hline $\begin{array}{l}\text { Wood and Paper Product Manufactur- } \\
\text { ing }\end{array}$ & -0.373 & -0.113 & 0.167 & 0.377 & 0.750 & 2.12 \\
\hline $\begin{array}{l}\text { Printing, Publishing and Recorded Me- } \\
\text { dia }\end{array}$ & -0.451 & -0.181 & 0.200 & 0.530 & 0.981 & 2.67 \\
\hline $\begin{array}{l}\text { Petroleum, Coal, Chemical and Associ- } \\
\text { ated Product Manufacturing }\end{array}$ & -0.362 & -0.139 & 0.192 & 0.426 & 0.788 & 2.20 \\
\hline $\begin{array}{l}\text { Non-Metallic Mineral Product Manufac- } \\
\text { turing }\end{array}$ & -0.449 & -0.139 & 0.244 & 0.496 & 0.945 & 2.57 \\
\hline Metal Product Manufacturing & -0.407 & -0.151 & 0.181 & 0.485 & 0.892 & 2.44 \\
\hline $\begin{array}{l}\text { Machinery and Equipment Manufactur- } \\
\text { ing }\end{array}$ & -0.488 & -0.185 & 0.218 & 0.534 & 1.023 & 2.78 \\
\hline Other Manufacturing & -0.425 & -0.144 & 0.211 & 0.446 & 0.871 & 2.39 \\
\hline Average & -0.427 & -0.158 & 0.202 & 0.477 & 0.904 & 2.47 \\
\hline
\end{tabular}

Table 2: MFP dispersion by industry, employing firms only

\begin{tabular}{lcccccc}
\hline & $\mathrm{p} 10$ & $\mathrm{p} 25$ & $\mathrm{p} 75$ & $\mathrm{p} 90$ & $\mathrm{p} 90-\mathrm{p} 10$ & $\exp (\mathrm{p} 90-\mathrm{p} 10)$ \\
\hline $\begin{array}{l}\text { Food, Beverage and Tobacco } \\
\text { Textile, Clothing, Footwear and Leather }\end{array}$ & -0.322 & -0.174 & 0.125 & 0.351 & 0.673 & 1.96 \\
$\begin{array}{l}\text { Manufacturing } \\
\text { Wood and Paper Product Manufactur- }\end{array}$ & -0.185 & -0.109 & 0.228 & 0.492 & 0.758 & 2.13 \\
$\begin{array}{l}\text { ing } \\
\text { Printing, Publishing and Recorded Me- }\end{array}$ & -0.270 & -0.122 & 0.153 & 0.337 & 0.607 & 1.63 \\
dia & & & & & \\
Petroleum, Coal, Chemical and Associ- & -0.259 & -0.107 & 0.159 & 0.344 & 0.603 & 1.83 \\
$\begin{array}{l}\text { ated Product Manufacturing } \\
\text { Non-Metallic Mineral Product Manufac- }\end{array}$ & -0.225 & -0.091 & 0.201 & 0.389 & 0.614 & 1.85 \\
$\begin{array}{l}\text { turing } \\
\text { Metal Product Manufacturing }\end{array}$ & -0.231 & -0.106 & 0.117 & 0.281 & 0.512 & 1.67 \\
$\begin{array}{l}\text { Machinery and Equipment Manufactur- } \\
\text { ing }\end{array}$ & -0.294 & -0.122 & 0.151 & 0.344 & 0.638 & 1.89 \\
Other Manufacturing & -0.228 & -0.097 & 0.182 & 0.356 & 0.584 & 1.79 \\
\hline Average & -0.253 & -0.109 & 0.164 & 0.355 & 0.609 & 1.84 \\
\hline
\end{tabular}


This reduces the average MFP gap between the 90th and 10th percentiles to $\exp ^{0.609}=1.84$, slightly lower than the figure in Syverson (2004). This difference is due to the wide productivity dispersion apparent in working proprietor only firms. Figure 1 plots estimated MFP against total firm size (employees plus working proprietors) across four groups of firms. The first three panels cover all employing firms - the first panel focuses on firms with employees but no working proprietors, while the second and third panels show firms with both employees and working proprietors (separating according to whether the count of working proprietors is greater or less than the number of employees). The last panel restricts to firms whose only labour input is from working proprietors. Comparison of the working proprietor only firms with all groups of employing firms shows substantially more dispersion among the former group.

While some of the dispersion in MFP among working proprietors is likely to reflect real differences in performance across these firms, much of it is likely due to measurement error in both capital and labour inputs. On the labour side, the LBD only includes information about the number of working proprietors drawing income during the year, but does not have any information about the extent of labour input. As such, full-time working proprietors are attributed the same labour input as those providing minimal (or no) input. Similarly, other inputs are also more likely to be mismeasured for these firms. For example, the capital input of sole proprietors may include a specified proportion of their housing expenses, as mandated by Inland Revenue, as well as the physical capital associated with the business. 
Figure 1: MFP dispersion and firm size

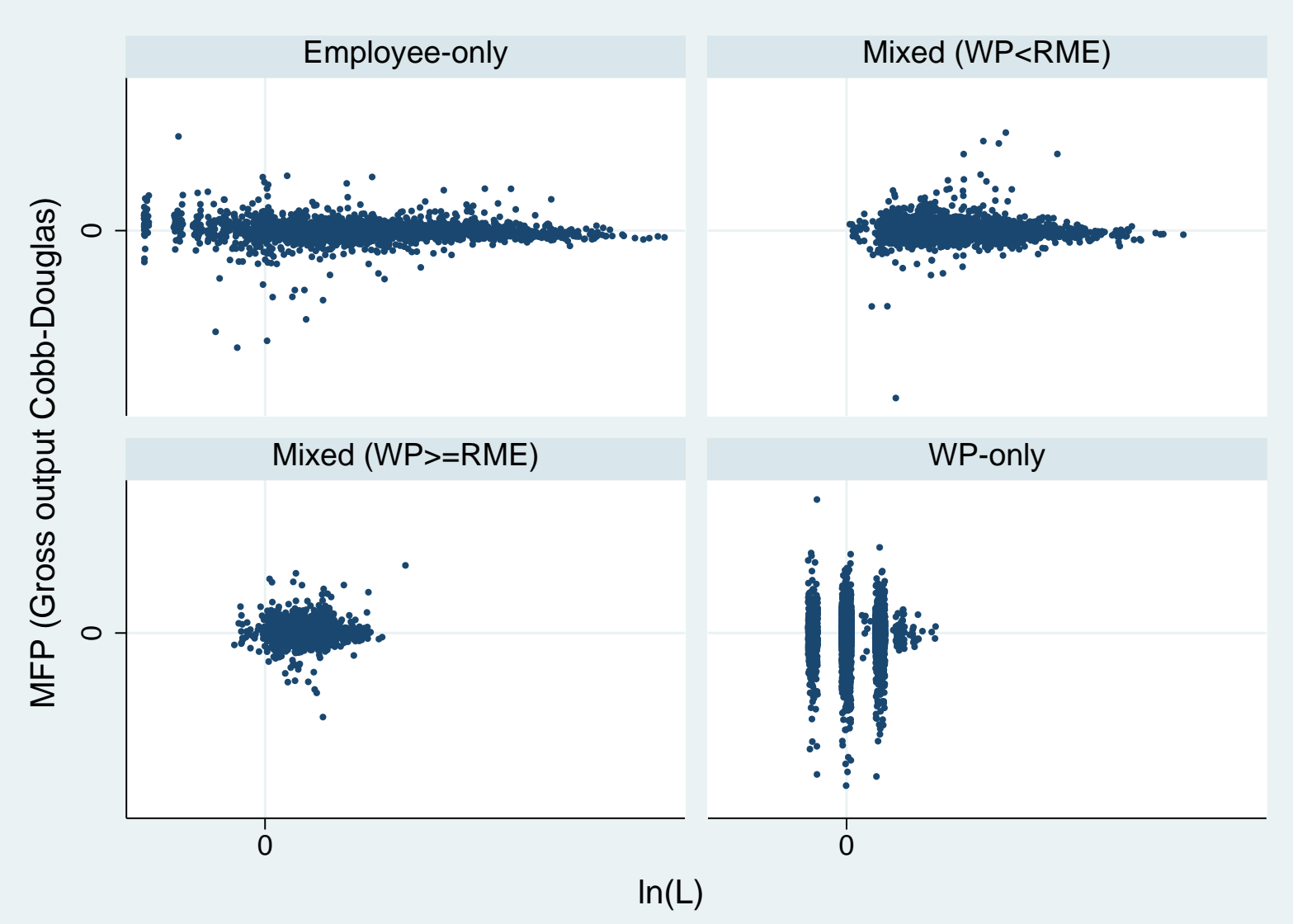

All observations have been jittered and outliers dropped in accordance with Statistics New Zealand confidentiality requirements. All four graphs are presented on the same scale. 


\section{Conclusion}

The results reported above are in no way an attempt to provide an answer to the question of whether the productivity distribution in New Zealand is in fact wider than that in comparator countries. Nor should it be used to infer anything about the relative degree of competition across different manufacturing industries within New Zealand. Rather, it is intended simply as an example to show that a simple restriction on data coverage, made by default in many other jurisdictions, is sufficient to generate measures of productivity dispersion which fall on either side of potential comparator. International comparisons of this type need to be carefully evaluated, with regard to both comparability of the data and methods and the appropriateness of inference in different contexts.

\section{References}

Fabling, R. \& Maré, D. (2015a). Addressing the absence of hours information in linked employer-employee data. Working Paper 15-17, Motu Economic and Public Policy Research.

Fabling, R. \& Maré, D. (2015b). Production function estimation using New Zealand's Longitudinal Business Database. Working Paper 15-15, Motu Economic and Public Policy Research.

Syverson, C. (2004). Product substitutability and productivity dispersion. The Review of Economics and Statistics, 86(2), 534-550.

Syverson, C. (2011). What determines productivity? Journal of Economic Literature, $49(2), 326-365$. 


\section{Recent Motu Working Papers}

All papers in the Motu Working Paper Series are available on our website www.motu.org.nz, or by contacting us oninfo@motu.org.nz or+64 49394250.

14-15 Sin, Isabelle, Richard Fabling, Adam Jaffe, David C. Maré and Lynda Sanderson. 2014. "Exporting, Innovation and the Role of Immigrants."

14-14 McLeod, Keith, Richard Fabling and David C. Maré. 2014. "Hiring New Ideas: International Migration and Firm Innovation in New Zealand."

14-13 Timar, Levente, Arthur Grimes and Richard Fabling. 2014. "That Sinking Feeling: The Changing Price of Disaster Risk Following an Earthquake."

14-12 Dorner, Zack, with Dean Hyslop. 2014. "Modelling Changing Rural Land Use in New Zealand 1997 to 2008 Using a Multinomial Logit Approach.”

14-11 Grimes, Arthur, Eyal Apatov, Larissa Lutchman and Anna Robinson. 2014. "Infrastructure's Long-Lived Impact on Urban Development: Theory and Empirics."

14-10 Maré, David C., Lynda Sanderson and Richard Fabling. 2014. "Earnings and Employment in Foreign-owned Firms."

14-09 Kerr, Suzi, and Vicki Duscha. 2014. "Going to the Source: Using an Upstream Point of Regulation for Energy in a National Chinese Emissions Trading System."

14-08 Fabling, Richard, Arthur Grimes and Levente Timar. 2014. "Natural Selection: Firm Performance Following the Canterbury Earthquakes."

14-07 Anastasiadis, Simon, Suzi Kerr, Wei Zhang, Corey Allan and William Power. 2014. "Land Use in Rural New Zealand: Spatial Land Use, Land-use Change, and Model Validation."

14-06 Di Tella, Rafael, and Robert MacCulloch. 2014. "Culture, Beliefs and Economic Performance."

14-05 Romanos, Carl, Suzi Kerr and Campbell Will. 2014. "Greenhouse Gas Emissions in New Zealand: A

Preliminary Consumption-Based Analysis."

14-04 Allan, Corey, Adam B. Jaffe and Isabelle Sin. 2014. "Diffusion of Green Technology: A Survey."

14-03 Timar, Levente, and Suzi Kerr. 2014. "Land-use Intensity and Greenhouse Gas Emissions in the LURNZ Model."

14-02 Grimes, Arthur. 2014. "Four Lectures on Central Banking."

14-01 Fabling, Richard, and Arthur Grimes. 2014. “Over the Hedge: Do Exporters Practice Selective Hedging?”

13-14 Fabling, Richard, Norman Gemmell, Richard Kneller and Lynda Sanderson. 2013. "Estimating Firm-Level Effective Marginal Tax Rates and the User Cost of Capital in New Zealand”.

13-13 Kerr, Suzi. 2013. "Managing Risks and Tradeoffs Using Water Markets".

13-12 Grimes, Arthur, and Sean Hyland. 2013. "Housing Market Dynamics and the GFC: The Complex Dynamics of a Credit Shock".

13-11 Anastasiadis, Simon and Suzi Kerr. 2013. "Mitigation and Heterogeneity in Management Practices on New Zealand Dairy Farms".

13-10 Grimes, Arthur and Sean Hyland. 2013. "Passing the Buck: Impacts of Commodity Price Shocks on Local Outcomes".

13-09 Allan, Corey, Arthur Grimes and Suzi Kerr. 2013. "Value and Culture."

13-08 Maré, David C., and Richard Fabling. 2013. “The Incidence and Persistence of Cyclical Job Loss in New Zealand". 